\title{
Erosive esophagitis with transient respiratory distress in newborns: a case report
}

\author{
Sasidharan $\mathbf{P}^{1}$, Jayasree. $\mathbf{C}^{2}$ \\ ${ }^{1}$ Dr. Sasidharan Ponthenkandath, Department of Pediatrics, Division of Neonatology, ${ }^{2}$ Dr. Jayasree Chandramati, both \\ authors are affiliated with Amrita Institute of Medical Sciences, Amrita University, Kochi, India.
}

Address for Correspondence: Dr Sasidharan Ponthenkandath, FAAP. Email: psasidha@gmail.com

\begin{abstract}
Isolated esophagitis is very rare in newborn infants at birth, although it may occur a few days or weeks later but is generally associated with gastritis or gastroesophageal reflux, infections or trauma. Respiratory distress is a very unusual clinical feature of esophagitis. We hereby report two newborns who presented with symptoms of respiratory distress at birth and had isolated erosive esophagitis. Symptoms resolved with treatment of esophagitis.
\end{abstract}

Key words: Erosive esophagitis, Newborn, Respiratory Distress.

\section{Introduction}

Respiratory distress in the newborn is the commonest medical problem encountered after birth. There are many causes that give rise to respiratory distress in the newborn although majority of them are due to disorders within the respiratory system. But practically every other organ system pathology may manifest as respiratory distress in the newborn and when evaluating a newborn with respiratory distress this fact has to be kept in mind $[1,2,3,4,5]$. We are reporting hereby two cases in which the newborns developed respiratory distress soon after birth with normal findings during clinical examination of the respiratory system including normal chest x-rays. The etiology seems to be due to isolated erosive esophagitis which has not been reported previously.

\section{Case Report}

Case 1: The patient was a full term female newborn born by spontaneous vaginal delivery to a 37 year old, gravida 6 para 4 , woman with a history of two spontaneous miscarriages in the past. The pregnancy was complicated with a history of mild maternal depression. She was also treated with a nicotine patch. Prenatal laboratory studies were unremarkable. The infant was delivered two days prior to the expected date of confinement and was quite active at birth requiring no resuscitation. The birth weight was $2510 \mathrm{gms}\left(10^{\text {th }}\right.$ percentile $)$, length $-45.5 \mathrm{~cm}$ ( $10^{\text {th }}$ percentile $)$, and head circumference - $32 \mathrm{~cm}$ (between $10^{\text {th }}$ to $25^{\text {th }}$ percentile). The infant developed mild tachypnea and grunting soon after birth and required supplemental oxygen up to $60 \%$ through a nasal cannula (1 liter/min flow) in order to maintain oxygen saturation above $90 \%$. Initial clinical impression was that the infant has transient tachypnea of the newborn with mild intrauterine growth restriction (discrepancy between head circumference and body weight percentiles). Initial chest x-ray was normal with no evidence suggestive of lung parenchymal pathology. Because of the respiratory distress, the infant was worked up to rule out sepsis and was treated with ampicillin and gentamicin. Supplemental oxygen was weaned off over the next two days.

The following were the laboratory values. Complete blood count: Hemoglobin- 22.1 Gm, WBC- 19,400, segmented neutrophils - $65 \%$, band neutrophils - 3\%, lymphocytes - $24 \%$, monocytes $-7 \%$, eosinophil - $1 \%$ and platelet count172,000. Cerebrospinal fluid examination revealed: protein- $114 \mathrm{mg} \%$; glucose- $64 \mathrm{mg} \%$ and white blood cells - 14 . The antibiotics were discontinued in 48 hours as the culture results were negative. Oral feedings were initiated by

Manuscript received: $5^{\text {th }}$ January 2017

Reviewed: $14^{\text {th }}$ January 2017

Author Corrected: $20^{\text {th }}$ January 2017

Accepted for Publication: $28^{\text {th }}$ January 2017 


\section{Case Report}

approximately 12 hours of age and the infant was noted to be periodically tachypneic (respiratory rates: 70-90/minute) with oxygen saturations dropping to below $85 \%$ measured by the pulse oximeter. The lowest oxygen saturation was $75 \%$. She was also noted to have desaturations with swallowing movements. A barium swallow was done to rule out gastroesophageal reflux at approximately 24 hours of age and it showed severe erosive esophagitis with no evidence of gastritis or reflux (Figure 1). Endoscopy on the same day revealed hyperemia with erosions and ulcers along the lower third of the esophagus with normal gastric mucosa. Infant was treated with ranitidine $6 \mathrm{mg}$ orally twice daily (five mg per kilogram per day).

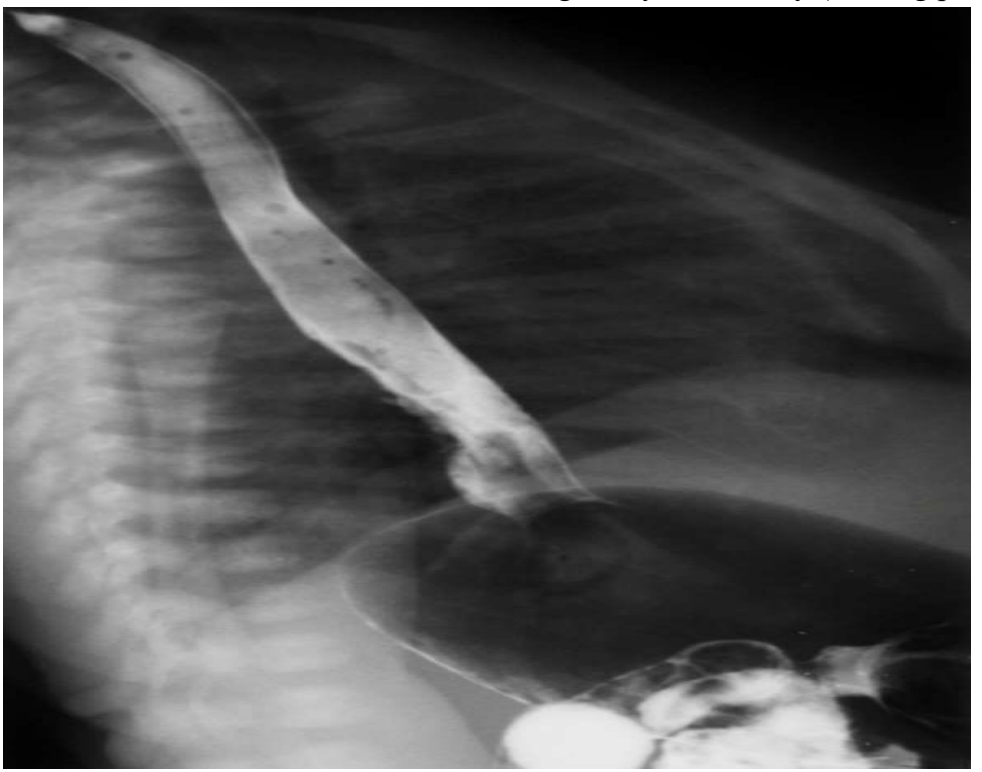

Figure-1: Barium swallow X-ray shows lower esophageal erosive esophagitis at two days of age. The erosion is along the lower posterior wall of the esophagus.

There was remarkable improvement in her symptoms and there were no further episodes of destaurations or tachypnea. The infant was discharged home on the sixth postnatal day with instructions to continue ranitidine for 14 days. A followup barium swallow done two weeks after discharge was completely normal (Figure 2).

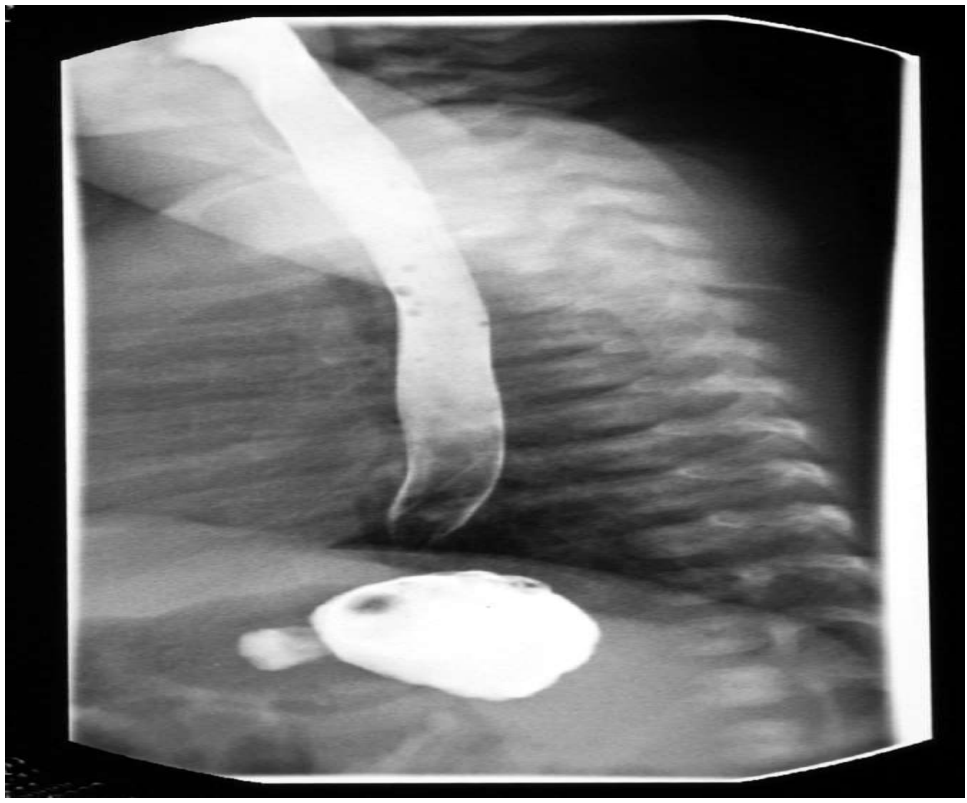

Figure-2: Barium swallow X- ray shows normal lower part of the esophagus, two weeks later. 
Case 2: A full term infant (birth weight: $2.8 \mathrm{Kg}$ ) was transferred to our center at approximately at 8 hours of age because of respiratory distress (tachypnea and desaturations) when feedings were initiated. The referring physician wanted to rule out an H-type trachea-esophageal fistula as a cause for the respiratory distress. Symptoms were mostly related to desaturations and tachypneas with no choking spells or cough with feedings. An endoscopy immediately revealed severe erosive esophagitis with normal gastric mucosa and with no evidence of gastritis. Isolated erosive esophagitis was diagnosed and infant was treated with sucralfate and ranitidine over the next 3 to 4 days. The symptoms resolved within 24 hours and the infant was discharged home on the $6^{\text {th }}$ day. Oral ranitidine was discontinued at two weeks of age. Both infants were doing well and asymptomatic at two weeks follow-up examination. Both infants did not have regurgitations or "spit ups" after feedings suggestive of significant reflux since birth.

\section{Discussion}

Although occasionally esophagitis can be asymptomatic in preterm infants, commonly most of the infants with esophagitis have either hematemesis or symptoms associated with feeding disorders or refusal to feed [6,7]. Esophagitis and gastritis may appear before the manifestation of any symptoms (bleeding, hematemesis, feeding disorders etc) which may appear afterwards. Esophagitis may exist in newborns without associated gastritis also as seen in our patients. The pathogenesis is thought to be due to the prolonged exposure of esophageal mucosa to acid and pepsin.

Factors giving rise to stress contribute to the etiology significantly. It has been reported that gastric ulcers can be present during fetal life [8,9]. Cytomegalovirus and helicobacter infection may also give rise to gastritis and ulceration. Milk protein allergy has also been implicated in the pathogenesis of neonatal gastritis. It is known that physiologic hypergastrinemia can exist in the first few days of life, which may be responsible for hyperacidity in the stomach and esophagus [5].

Lichtenberger et al have reported that hypergastrinemia may be related to high concentrations of volatile amines in the amniotic fluid $[10,11]$. The oxyntic glands, which are responsible for the acid secretion in the stomach, are present in the fetus during second trimester.

This is an indication that acid secretion can occur during fetal life although at birth most of the newborns have gastric $\mathrm{pH}$ of approximately 6 . The gastric acid output increases significantly during the first two hours of life and the $\mathrm{pH}$ drops to approximately $3.2[12,13]$.

We did not measure serum gastrin levels in our patients. Esophagitis has also been described with trauma by the passage of nasogastric feeding tube or suction catheters $[14,15]$ although our patients were not suctioned or fed through nasogastric tube. Aronson et al had reported spontaneous rupture of the esophagus in the newborn $[15,16]$. He speculated that a sudden increase in intra- abdominal pressure during delivery might be one of the reasons that may give rise to rupture of the esophagus; however, such perforations are extremely rare. Incoordination of cricopharyngeus or upper esophageal muscles during emesis can theoretically give rise to a closed tube with high pressures leading to the risk for rupture. In such cases rupture of the esophagus generally results in pneumothorax and significant respiratory distress.

Probably, intrauterine stress with fetal growth restriction might have contributed to the pathogenesis of esophagitis in our first patient. Instead of the typical symptoms of bleeding, hematemesis, bloody stools, or feeding disorders, our patient had transient respiratory distress perhaps as a manifestation of pain which is known to give rise to hypoxemia (oxygen desaturations) in the newborn [20].

The prognosis of this condition is excellent in most cases with prompt medical therapy. Although gastroesophageal reflux without esophagitis is common in newborns they do not require treatment as most of them will resolve spontaneously [21].

The gold standard in the diagnosis of esophagitis and gastritis is endoscopy [17-18]. Indications for endoscopy include upper GI bleeding, suspected GERD (gastroesophageal reflux disease), mucosal biopsy and esophagitis. Most of these procedures are done with fiberoptic endoscope at the bed side with minimal or no sedation.

Anesthesia is not required in newborns. We performed an upper GI contrast study with an esophagram in the first patient which was also quite diagnostic of the esophagitis, due to presence of the erosion. An endoscopy confirmed the diagnosis. The upper GI contrast study was repeated two weeks later after treating the infant with ranitidine and it showed complete resolution of the esophageal ulceration. 


\section{Conclusion}

We have presented a clinical scenario of significant erosive esophagitis in two newborns at birth whose main presenting symptoms were tachypnea and intermittent cyanosis, requiring supplemental oxygen. The infant's symptoms subsided after they were treated with $\mathrm{H}_{2}$ blockers (ranitidine).

The radiological abnormality detected had resolved completely within two weeks of life. Endoscopies were not repeated as the infants were totally asymptomatic at follow-up examination.

To our knowledge these are the first case reports of erosive esophagitis present at birth presenting with symptoms of respiratory distress.

These cases illustrate that an isolated esophagitis should also be included in the differential diagnosis of respiratory distress in the newborn if, chest $\mathrm{x}$-ray findings are normal and all other causes of respiratory distress have been ruled out.

Clinically symptoms seem to get worse with feeds or swallowing in these infants. Although endoscopy is considered the gold standard in the diagnosis of esophagitis, dilute barium or non-ionic water soluble contrast study which is far less non-invasive is adequate in the diagnosis of esophagitis of newborns which can be performed in smaller community hospitals.

Funding: Nil, Conflict of interest: None initiated, Perission from IRB: Yes

\section{References}

1. Edwards MO, Kotecha SJ, Kotecha S. Respiratory distress of the term newborn infant. Paediatr Respir Rev. 2013 Mar;14(1):29-36; quiz 36-7. doi: 10.1016/j. prrv. 2012.02.002. Epub 2012 Mar 2.

2. Wilmott RW, Boat TF, Bush A, Chernick V, Deterding RR. Kendig and Chernick's Disorders of the Respiratory Tract in Children. Philadelphia, PA: Elsevier Saunders; 2012.

3. Aly H. Respiratory disorders in the newborn: identification and diagnosis. Pediatr Rev. 2004 Jun;25 (6):201-8.

4. Warren JB, Anderson JM. Newborn respiratory disorders. Pediatr Rev. 2010 Dec;31(12):487-95; quiz 496. doi: 10.1542/pir.31-12-487.
5. Suzanne Reutter, Chuanpit Moser, Michelle Baack. Respiratory Distress in the Newborn. Pediatrics in Review, 2014, vol.35 issue 10.

6. Maki M, Ruuska T, Kuusela AL, Karikoski-Leo R, Ikonen RS. High prevalence of asymptomatic esophageal and gastric lesions in preterm infants in intensive care. Critical Care Medicine.1993, 21(12): 1863-7.

7. Bedu A, Faure C, Sibony O, Vuillard E, Mougenot JF, Aujard Y. Prenatal gastrointestinal bleeding caused by esophagitis and gastritis. J Pediatr. 1994 Sep; 125 (3):465-7.

8. Wen HH, Chen MH, Ho MM, Hwang KC. Fetal gastric ulcer presenting with bloody amniotic fluid. Journal of Pediatric Gastroenterology \& Nutrition. 1992, $15(4): 455-7$.

9. Lucas A, Adrian TE, Christofides N, Bloom SR, Aynsley-Green A. Plasma motilin, gastrin, and enteroglucagon and feeding in the human newborn. Arch Dis Child. 1980 Sep;55(9):673-7.

10. Lichtenberger LM, Gardner JW, Barreto JC, Morriss $\mathrm{FH}$, Jr. Evidence for a role of volatile amines in the development of neonatal hypergastrinemia. Journal of Pediatric Gastroenterology \& Nutrition. 1991, 13(4): 342-6.

11. EBERS DW, GIBBS GE, SMITH DI. Gastric acidity on the first day of life. Pediatrics. 1956 Nov; 18(5):8002 .

12. Grand RJ, Watkins JB, Torti FM. Development of the human gastrointestinal tract. A review. Gastroenterology. 1976 May;70(5 PT.1):790-810.

13. Azimi PH, Willert J, Petru A. Severe esophagitis in a newborn infant. Pediatric Infectious Disease Journal. 1996, 15(4):385.

14. Taylor MJ, McCulloch DL. Visual evoked potentials in infants and children. J Clin Neurophysiol. 1992 Jul;9(3):357-72.

15. Aaronson A, Cywes S, Louw JH. Spontaneous esophageal rupture in the newborn. J Pediatr Surg. 1975 Aug;10(4):459-66. 
16. Hyman PE. Gastroesophageal reflux: one reason why baby won't eat. J Pediatr. 1994 Dec;125(6 Pt 2): S103-9.

17. de Boissieu D, Dupont C, Barbet JP, Bargaoui K, Badoual J. Distinct features of upper gastrointestinal endoscopy in the newborn. Journal of Pediatric Gastroenterology \& Nutrition. 1994 18(3):334-8.

18. Sherman NJ, Clatworthy HW Jr. Gastrointestinal bleeding in neonates: a study of 94 cases. Surgery. 1967 Oct; 62(4):614-9.

19. Borowitz SM. Ulcerative esophagitis. A rare source of upper gastrointestinal bleeding in a neonate. Use of fiberoptic endoscopy for diagnosis. Clinical Pediatrics. 1989, 28(2):89-91.

20. Bartocci M, Bergqvist LL, Lagercrantz H, Anand KJ. Pain activates cortical areas in the preterm newborn brain. Pain. 2006 May;122(1-2):109-17. Epub 2006 Mar 13.

21. Lightdale JR, Gremse DA; Section on Gastroenterology, Hepatology, and Nutrition. Gastroesophageal reflux: management guidance for the pediatrician. Pediatrics. 2013 May;131(5):e1684-95. doi: 10. 1542 /peds. 2013-0421. Epub 2013 Apr 29.

\section{How to cite this article?}

Sasidharan P, Jayasree. C. Erosive esophagitis with transient respiratory distress in newborns: a case report. J PediatrRes.2017;4(01):47-51.doi:10.17511/ijpr.2017.i01.10 